\title{
Ocorrência e fatores de risco associados à infecção por Corynebacterium pseudotuberculosis em caprinos e ovinos do semiárido paraibano ${ }^{1}$
}

\author{
José Sóstenes L. Andrade², Sérgio S. Azevedo² ${ }^{2}$ José Andreey A. Teles², \\ Silvano S.S. Higino e Edisio O. Azevedo ${ }^{2 *}$
}

\begin{abstract}
Andrade J.S.L., Azevedo S.S., Teles J.A.A., Higino S.S.S. \& Azevedo E.O. 2012. [Occurrence and risk factors associated with the Corynebacterium pseudotuberculosis infection in sheep and goats from the semiarid region of the Paraiba state, Northeastern Brazil.] Ocorrência e fatores de risco associados à infecção por Corynebacterium pseudotuberculosis em caprinos e ovinos do semiárido paraibano. Pesquisa Veterinária Brasileira 32(2):116-120. Unidade Acadêmica de Medicina Veterinária, Centro de Saúde e Tecnologia Rural, Universidade Federal de Campina Grande, Av. Universitária s/n, Patos, PB 58700-970, Brazil. E-mail: edisio@cstr.ufcg.edu.br

This study aimed to determine the occurrence and risk factors associated with Corynebacterium pseudotuberculosis infection in goats and sheep in semiarid region of Paraiba State, Northeastern Brazil. Of the 640 animals examined, 7.7\% (49/640) had clinical evidence of caseous lymphadenitis. In 59.2\% (29/49) of these animals there was only the scars of previously ruptured abscesses and in $40.8 \%(20 / 49)$ of the animals abscesses were intact. Of these 20 animals 13 (65\%) goats had 14 abscesses, whereas seven (35\%) sheep had eight abscesses. In both species, pre-scapular lymph node was the most involved. C. pseudotuberculosis was the agent most frequently isolated, in 15 (68.2\%) samples, and in one (4.5\%) coagulase-negative Staphylococcus was isolated, one (4.5\%) Enterococcus sp., one (4.5\%) Proteus mirabilis and Pseudomonas aeruginosa, and in four $(18.2 \%)$ samples there was no bacterial growth. The final logistic regression model showed that animals from herds where their owners let the abscesses break naturally presented larger odds of caseous lymphadenitis (odds ratio $=8.19,95 \% \mathrm{CI}=1.75-38.25, \mathrm{p}=0.008$ ). We conclude that goat/sheep owners of the region should adopt preventive measures in their herds, such as early opening and drainage of superficial abscesses, and appropriate destination of the content. Such measures, in addition to regular inspection of the flock, disposal of diseased animals and introduction of non-infected animals will contribute to the control of this infection.
\end{abstract}

INDEX TERMS: Caseous lymphadenitis, superficial lymph nodes, microbiology, epidemiology.

RESUMO.- Este trabalho teve como objetivo determinar a ocorrência e os fatores de risco associados à infecção por Corynebacterium pseudotuberculosis em caprinos e ovinos do semiárido da Paraiba. De 640 animais examinados, 7,7\% (49/640) apresentavam evidências clínicas de linfadenite caseosa. Em 59,2\% (29/49) destes animais

\footnotetext{
${ }^{1}$ Recebido em 20 de agosto de 2011.

Aceito para publicação em 10 de outubro de 2011.

${ }^{2}$ Unidade Acadêmica de Medicina Veterinária (UAMV), Centro de Saúde e Tecnologia Rural (CSTR), Universidade Federal de Campina Grande (UFCG), Av. Universitária s/n, Bairro Santa Cecília, Patos, PB 58700-970, Brasil. *Autor para correspondência: edisio@cstr.ufcg.edu.br
}

havia apenas as cicatrizes de abscessos anteriormente rompidos; em 40,8\% (20/49) dos animais, os abscessos estavam intactos. Desses 20 animais, $13(65 \%)$ caprinos apresentaram 14 abscessos, enquanto que sete (35\%) ovinos apresentaram oito abscessos. Em ambas as espécies, o linfonodo pré-escapular foi o mais acometido. No exame microbiológico, constatou-se que $C$. pseudotuberculosis foi o agente mais frequentemente isolado, em 15 (68,2\%) amostras; em uma $(4,5 \%)$ foi isolado Staphylococcus coagulase negativa; uma (4,5\%) Enterococcus sp.; uma (4,5\%) o Proteus mirabilis e Pseudomonas aeruginosa; e em quatro $(18,2 \%)$ amostras não houve crescimento bacteriano. 
O modelo final de regressão logística mostrou que animais provenientes de rebanhos em que seus proprietários deixavam os abscessos romperem naturalmente tiveram maior chance de apresentar linfadenite caseosa (odds ratio $=8,19$; IC $95 \%=1,75-38,25 ; p=0,008$ ). Conclui-se que os caprinovinocultores da região devem adotar medidas profiláticas em seus rebanhos, como abertura e drenagem precoce dos abscessos superficiais e destino adequado do conteúdo. Tais medidas, associadas à inspeção periódica do rebanho, descarte de animais doentes e não introdução de animais infectados, contribuirão significativamente para o controle desta infecção.

TERMOS DE INDEXAÇÃO: Linfadenite caseosa, linfonodos superficiais, cultivo microbiologia, epidemiologia.

\section{INTRODUÇÃO}

A caprinovinocultura é uma atividade em plena expansão e de grande importância para o desenvolvimento sócio-econômico do semiárido brasileiro, particularmente na região Nordeste. Evoluindo de criações voltadas para a subsistência, nos últimos anos ocorreram mudanças significativas para a consolidação da cadeia produtiva da caprinovinocultura no Brasil. Nesse período, a atividade despertou maior atenção de governantes, técnicos e produtores, acarretando mudanças significativas, destacando-se a intensificação da pesquisa voltada para produção de animais e beneficiamento de seus produtos, crescimento do nível de organização dos produtores, aumento da absorção das novas tecnologias, maior atuação dos agentes financeiros para facilitar o acesso ao crédito e, o mais importante, aumento da demanda por produtos derivados de caprinos e ovinos (Medeiros et al. 2005, Carvalho 2011). Entretanto, apesar do impulso mercadológico, a produtividade da caprinovinocultura no Brasil ainda é baixa, principalmente devido às doenças infecciosas, dentre as quais se destaca a linfadenite caseosa.

Esta é definida como uma doença contagiosa crônica que acomete ovinos e caprinos, caracterizada por lesões purulentas e caseosas nos linfonodos e, ocasionalmente, pulmões, baço, rins, fígado e sistema nervoso central (Alves et al. 2007, Radostits et al. 2007, Riet-Correa 2007, Smith \& Sherman 1994).

A linfadenite caseosa é causada por Corynebacterium pseudotuberculosis, bactéria Gram-positiva, não esporulada, aeróbica e parasita intracelular facultativa de macrófagos. Produz uma exotoxina, a fosfolipase D, que atua como esfingomielinase, que é dermonecrótica, hemolítica, causa supuração e tem ação nas células endoteliais, causando aumento da permeabilidade dos vasos sanguíneos e linfáticos facilitando desta maneira a invasão bacteriana (Alves et al. 2007, Fontaine \& Baird 2008, Souza et al. 2011).

A doença é endêmica no Brasil, e tem uma prevalência clínica variável de $5 \%$ a $50 \%$, sendo mais comum em caprinos e ovinos deslanados (Souza et al. 2011). A principal via de eliminação do agente é o conteúdo dos abscessos que, quando supuram, contaminam o ambiente. A transmissão ocorre por contato direto com as secreções dos abscessos ou com agulhas, aparelhos de tosquia, instalações, fômites e banhos de imersão contaminados com o agente (Alves et al. 2007, Radostits et al. 2007, Riet-Correa 2007).

Considerando a importância da caprinovinocultura para a região Nordeste do Brasil, particularmente para o Estado da Paraíba e a inexistência de informações acerca dos possíveis fatores que podem predispor a ocorrência de linfadenite caseosa, o presente estudo teve como objetivos determinar a ocorrência e identificar fatores de risco associados à infecção por $C$. pseudotuberculosis em caprinos e ovinos do semiárido paraibano.

\section{MATERIAL E MÉTODOS}

A Paraíba se encontra geograficamente dividida em quatro mesorregiões (Sertão Paraibano, Borborema, Agreste Paraibano e Mata Paraibana) e 23 microrregiões. 0 presente trabalho foi conduzido nas microrregiões de Piancó e Itaporanga, pertencentes à mesorregião do Sertão Paraibano (Fig.1).

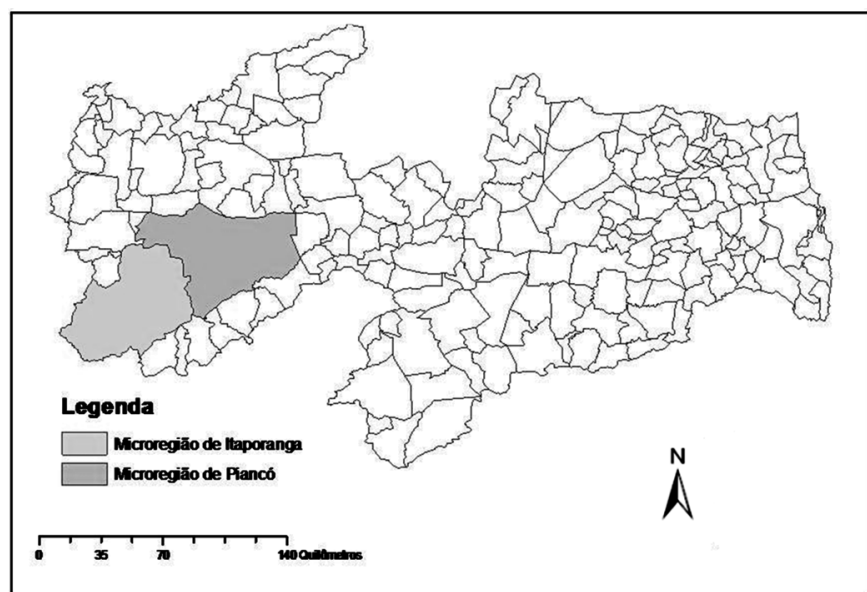

Fig.1. Mapa do Estado da Paraiba demonstrando as microrregiões de Piancó e Itaporanga.

A microrregião de Piancó é constituída por nove municípios: Piancó, Olho Dágua, Emas, Catingueira, Aguiar, Igaracy, Nova Olinda, Santana dos Garrotes e Coremas. Já a microrregião de Itaporanga é constituída por 11 municípios: Boa Ventura, Conceição, Curral Velho, Diamante, Ibiara, Itaporanga, Pedra Branca, Santa Inês, Santana de Mangueira, São José do Caiana e Serra Grande.

Neste trabalho foram utilizados 640 animais de ambos os sexos, sem raça definida, sendo 320 caprinos e 320 ovinos, procedentes de 32 propriedades localizadas em quatro municípios da microrregião de Piancó (Piancó, Catingueira, Santana dos Garrotes e Olho Dágua) e quatro na microrregião de Itaporanga (Itaporanga, Conceição, Curral Velho e São José de Caiana). Não foram adotados critérios probabilísticos, e as propriedades foram selecionadas a partir do consentimento dos proprietários.

No momento da visita à propriedade, foi aplicado um questionário epidemiológico contendo 47 questões que abordavam características referentes à produção e manejo, grau de instrução do proprietário e aos rebanhos (tipo de exploração, instalações, manejo geral e problemas sanitários).

Durante as visitas, os animais foram submetidos a exame clínico por inspeção e palpação dos linfonodos superficiais parotídeos, submandibulares, pré-escapulares, pré-crurais, poplíteos, femurais e mamários para a identificação de lesões sugestivas de linfadenite caseosa, bem como foram investigadas evidências de sinais de cicatrização na pele devido aos abscessos rompidos. Na constatação de abscessos, coletou-se o conteúdo purulento com 
os devidos cuidados assépticos e foi procedido o acondicionamento em sacos plásticos, identificação e remessa sob refrigeração ao laboratório.

No laboratório, as amostras foram semeadas em Agar Sangue Ovino 5\% (Himedia ${ }^{\circledR}$, Bhaveshwar, Mumbai, India) e Brain Heart Infusion broth (BHI-Himedia ${ }^{\circledR}$, Bhaveshwar, Mumbai, India), incubadas a $37^{\circ} \mathrm{C}$ em aerobiose, sendo realizadas leituras com 24-72 horas de incubação. Nos microrganismos isolados foram realizados exames bacterioscópicos pelo método de Gram e submetidos às provas de identificação: produção de catalase, urease e indol; motilidade em ágar semi-sólido; hidrólise da esculina; acidificação de carboidratos; oxidação-fermentação em meio de Hugh e Leifson; redução de nitrato; cultivo em TSI e ágar citrato de Simmons; testes de Camp, VM/VP e oxidase. As bactérias foram identificadas baseando-se no Manual of Clinical Microbiology (Murray et al. 1999).

Para a análise dos fatores de risco associados à linfadenite caseosa foi utilizado o procedimento de estudo observacional do tipo transversal (Thrusfield 1995) e foi efetuada com os dados colhidos nos questionários epidemiológicos. As variáveis independentes (possíveis fatores de risco) foram categorizadas e codificadas, deixando-se a categoria de menor risco com o menor código (Latorre 2004). Esta categoria de menor risco foi considerada a referência para a comparação com as demais.

A análise de fatores de risco foi efetuada em duas etapas: análise univariada e análise multivariada. Na análise univariada, cada variável independente foi cruzada com a variável dependente (condição sanitária do animal, ou seja, positivo ou negativo no isolamento de C. pseudotuberculosis). As que apresentaram um valor de $\mathrm{p} \leq 0,2$ pelo teste de qui-quadrado ou teste exato de Fisher (Zar 1999) foram selecionadas e usadas na análise multivariada, utilizando-se a regressão logística múltipla (Hosmer Junior \& Lemeshow 1989). 0 nível de significância adotado na análise múltipla foi de $5 \%$, e todas as análises foram realizadas com o programa SPSS 13.0 for Windows.

\section{RESULTADOS}

De um total de 640 animais examinados, 7,7\% (49/640) apresentaram evidências clínicas de linfadenite caseosa. Em 59,2\% (29/49) destes animais havia apenas as cicatrizes de abscessos anteriormente rompidos; em 40,8\% (20/49) dos animais, os abscessos estavam intactos, sendo coletado o seu conteúdo para análises microbiológicas.

No que se refere ao número de abscessos por espécie afetada, verificou-se que de 20 animais de ambas as espécies, 13 (65\%) caprinos apresentaram 14 abscessos, enquanto que sete (35\%) ovinos apresentaram oito abscessos (Quadro 1), totalizando 22 abscessos. Os animais de número 37 (ovino) e 153 (caprino) apresentaram abscessos em mais de um linfonodo. Em ambas as espécies, o linfonodo pré-escapular foi o mais acometido (Quadro 2).

No exame microbiológico, constatou-se que Corynebacterium pseudotuberculosis foi o agente mais frequentemente isolado, em 15 (68,2\%) amostras; em uma (4,5\%) foi isolado Staphylococcus coagulase negativa; uma $(4,5 \%)$

Quadro 1. Distribuição e identificação de bactérias provenientes de abscessos em linfonodos superficiais de caprinos e ovinos do semiárido paraibano

\begin{tabular}{|c|c|c|c|c|}
\hline $\begin{array}{c}\text { Identificação } \\
\text { do animal }\end{array}$ & Procedência & Espécie & $\begin{array}{c}\text { Linfonodos } \\
\text { afetados }\end{array}$ & Agente isolado \\
\hline 4 & Piancó & Caprina & Pré crural & C. pseudotuberculosis \\
\hline 19 & Piancó & Caprina & Pré-escapular & Staphylococcus coag. Negative \\
\hline 31 & Piancó & Ovina & Pré crural & Proteus mirabilis / Pseudomonas aeruginosa \\
\hline 37 & Piancó & Ovina & Pré crural & Sem crescimento \\
\hline 37 & Piancó & Ovina & Pré-escapular & C. pseudotuberculosis \\
\hline 38 & Piancó & Ovina & Pré-escapular & C.pseudotuberculosis \\
\hline 65 & Piancó & Caprina & Pré-escapular & Sem crescimento \\
\hline 67 & Piancó & Caprina & Pré crural & Enterococcus SP \\
\hline 98 & Catingueira & Ovina & Pré-escapular & C. pseudotuberculosis \\
\hline 110 & Catingueira & Ovina & Parotídeo & Sem crescimento \\
\hline 134 & Catingueira & Caprina & Pré-escapular & C. pseudotuberculosis \\
\hline 136 & Catingueira & Caprina & Pré crural & C. pseudotuberculosis \\
\hline 138 & Catingueira & Caprina & Retro-mamario & C. pseudotuberculosis \\
\hline 139 & Catingueira & Caprina & Sub-mandibular & C. pseudotuberculosis \\
\hline 140 & Catingueira & Caprina & Pré-escapular & C. pseudotuberculosis \\
\hline 153 & Catingueira & Caprina & Sub-mandibular & C. pseudotuberculosis \\
\hline 153 & Catingueira & Caprina & Pré-escapular & C. pseudotuberculosis \\
\hline 198 & Itaporanga & Ovina & Sub-mandibular & Sem crescimento \\
\hline 247 & Santana dos Garrotes & Ovina & Pré-escapular & C. pseudotuberculosis \\
\hline 390 & Conceição & Caprina & Parotídeo & C. pseudotuberculosis \\
\hline 582 & Olho Dágua & Caprina & Pré-escapular & C. pseudotuberculosis \\
\hline 602 & Olho Dágua & Caprina & Pré-escapular & C. pseudotuberculosis \\
\hline
\end{tabular}

Quadro 2. Distribuição de abscessos em linfonodos superficiais de caprinos e ovinos criados no semiárido paraibano segundo a espécie animal

\begin{tabular}{lcccc}
\hline \multicolumn{1}{c}{ Localização dos abscessos } & Ovinos & $\%$ & Caprinos & $\%$ \\
\hline Linfonodo pré-escapular & 4 & 50 & 7 & 50 \\
Linfonodo pré-crural & 2 & 25 & 3 & 21,4 \\
Linfonodo parotídeo & 1 & 12,5 & 1 & 7,1 \\
Linfonodo sub-mandibular & 1 & 12,5 & 2 & 14,3 \\
Linfonodo mamário & 0 & 0 & 1 & 7,1 \\
Total & 8 & 100 & 14 & 100
\end{tabular}

Enterococcus sp.; uma (4,5\%) o Proteus mirabilis e Pseudomonas aeruginosa; e em quatro $(18,2 \%)$ amostras não houve crescimento bacteriano (Quadro 1).

Considerando a faixa etária dos animais com presença de abscessos foi possível isolar C. pseudotuberculosis com maior frequência na faixa etária de até 12 meses (40\%), seguida das faixas etárias acima de 36 meses (26,7\%), 12-24 meses (20\%), e 24-36 meses (13,3\%), totalizando $68,2 \%$ de todas as amostras (Quadro 3). 
Quadro 3. Distribuição de caprinos e ovinos positivos para Corynebacterium pseudotuberculosis criados no semiárido paraibano, de acordo com a faixa etária

\begin{tabular}{|c|c|c|c|c|c|c|c|}
\hline \multirow[t]{3}{*}{ Idade } & \multicolumn{4}{|c|}{ Espécie animal } & \multirow{3}{*}{$\begin{array}{l}\text { Total } \\
\text { Idade }\end{array}$} & \multirow{3}{*}{$\begin{array}{c}\text { Total } \\
\text { Positivo }\end{array}$} & \multirow{3}{*}{$\begin{array}{c}\text { Proporção } \\
\text { por idade (\%) }\end{array}$} \\
\hline & \multicolumn{2}{|c|}{ Ovinos } & \multicolumn{2}{|c|}{ Caprinos } & & & \\
\hline & $\mathrm{n}$ & Positivo & $\mathrm{n}$ & Positivo & & & \\
\hline Até 12 meses & 3 & 1 & 6 & 5 & 9 & 6 & 40 \\
\hline 12-24 meses & 3 & 1 & 2 & 2 & 5 & 3 & 20 \\
\hline 24-36 meses & - & - & 2 & 2 & 2 & 2 & 13,3 \\
\hline > 36 meses & 2 & 2 & 4 & 2 & 6 & 4 & 26,7 \\
\hline Total & 8 & 4 & 14 & 11 & 22 & 15 & 68,2 \\
\hline
\end{tabular}

$\mathrm{Na}$ análise de fatores de risco associados à infecção por C. pseudotuberculosis, as variáveis mais associadas, na análise univariada, foram: escolaridade do proprietário $(\mathrm{p}<0,001)$, residir na propriedade $(\mathrm{p}=0,028)$, tipo de castração $(\mathrm{p}<0,001)$, frequência de administração de vermífugos $(\mathrm{p}=0,029)$, vermifugar animais recém-chegados $(\mathrm{p}=0,036)$, isolar os animais com linfadenite caseosa $(p=0,030)$ e deixar o abscesso romper naturalmente $(\mathrm{p}<0,001)$ (Quadro 4$)$. 0 modelo final de regressão logística mostrou que animais provenientes de rebanhos em que seus proprietários deixavam os abscessos romperem naturalmente tiveram maior probabilidade de apresentar linfadenite caseosa (odds ratio = 8,19; IC 95\% =1,75-38,25; $\mathrm{p}=0,008$ ) (Quadro 5).

\section{DISCUSSÃO E CONCLUSÕES}

O conhecimento da ocorrência e distribuição da linfadenite caseosa em rebanhos de ovinos e caprinos criados nas microrregiões de Piancó e Itaporanga, Estado da Paraiba, até então desconhecido, nos chamou atenção e interesse em buscar informações que possibilitasse solucionar questões referentes à doença. Embora não se tenha utilizado uma amostragem com critérios probabilísticos, foi possível o levantamento de informações importantes acerca da ocorrência e distribuição da doença.

De um total de 640 animais examinados, 7,7\% (49/640) apresentavam evidências clínicas de linfadenite caseosa, caracterizada por cicatrizes e/ou abscessos. Resultados similares foram observados por Langenegger et al. (1991), que considerando o conjunto de 760 caprinos em 13 rebanhos no Estado do Rio de Janeiro, verificaram, no exame clínico, que $93(12,2 \%)$ caprinos apresentavam linfonodos abscedados e/ou cicatrizes na pele resultante do rompimento de abscessos.

Souza et al. (2011) examinaram 1466 ovinos abatidos em um frigorífico do Estado da Paraíba e observaram que $236(15,9 \%)$ dos animais apresentaram lesões macroscópicas semelhantes à linfadenite caseosa, frequência essa superior a encontrada no presente trabalho. No entanto, vale ressaltar que naquele trabalho foram observadas lesões antes e após o abate, o que possibilita a verificação de lesões internas associadas à doença subclínica, que representa um dos principais entraves no controle da infecção. De qualquer maneira, a frequência de linfadenite caseosa clínica encontrada no presente trabalho pode ser considerada alta, o que normalmente ocorre na região Nordeste em comparações com outras regiões do Brasil, provavelmente como consequência da presença de inúmeras plantas cactáceas que causam ferimentos na pele de caprinos e ovinos,
Quadro 4. Distribuição das variáveis mais associadas à infecção de caprinos e ovinos por Corynebacterium pseudotuberculosis na análise univariada, de acordo com a probabilidade de ocorrência ao acaso (p)

\begin{tabular}{|c|c|c|c|}
\hline \multirow[t]{2}{*}{ Variáveis } & \multicolumn{2}{|c|}{$\begin{array}{c}\text { Exposição/Condição } \\
\text { sanitária }\end{array}$} & \multirow[t]{2}{*}{$\mathrm{P}$} \\
\hline & $\begin{array}{l}\text { Expostos/ } \\
\text { Positivos }\end{array}$ & $\begin{array}{l}\text { Expostos/ } \\
\text { Negativos }\end{array}$ & \\
\hline \multicolumn{4}{|l|}{ Escolaridade do proprietário } \\
\hline Analfabeto & $0 / 14$ & $60 / 626$ & $<$ \\
\hline $1^{\circ}$ grau & $4 / 14$ & $316 / 626$ & 0,001 \\
\hline $2^{\circ}$ grau & $1 / 14$ & $139 / 626$ & \\
\hline Nível Superior & $9 / 14$ & $111 / 626$ & \\
\hline \multicolumn{4}{|l|}{ Residir na propriedade } \\
\hline Não & $12 / 14$ & $328 / 626$ & 0,028 \\
\hline Sim & $2 / 14$ & $298 / 626$ & \\
\hline \multicolumn{4}{|l|}{ Tipo de castração } \\
\hline Cirurgia & $0 / 14$ & $20 / 626$ & $<$ \\
\hline Burdizo & $0 / 14$ & $120 / 626$ & 0,001 \\
\hline Liga & $1 / 14$ & $199 / 626$ & \\
\hline Torção & $0 / 14$ & $40 / 626$ & \\
\hline Não faz & $8 / 14$ & $192 / 626$ & \\
\hline Burdizo e Liga & $5 / 14$ & $15 / 626$ & \\
\hline \multicolumn{4}{|c|}{ Frequência de administração de vermífugos } \\
\hline Não faz & $8 / 14$ & $492 / 626$ & 0,029 \\
\hline $1-2$ vezes/ano & $1 / 14$ & $59 / 626$ & \\
\hline $3-4$ vezes/ano & $5 / 14$ & $75 / 626$ & \\
\hline \multicolumn{4}{|c|}{ Vermifugar animais recém-chegados } \\
\hline Não & $13 / 14$ & $387 / 626$ & 0,036 \\
\hline Sim & $1 / 14$ & $239 / 626$ & \\
\hline \multicolumn{4}{|c|}{ Isolar os animais com linfadenite caseosa } \\
\hline Não & $14 / 14$ & $486 / 626$ & 0,030 \\
\hline Sim & $0 / 14$ & $140 / 626$ & \\
\hline \multicolumn{4}{|c|}{ Deixa o abscesso romper naturalmente } \\
\hline Não & $2 / 14$ & $398 / 626$ & $<$ \\
\hline Sim & $12 / 14$ & $228 / 626$ & 0,001 \\
\hline
\end{tabular}

Quadro 5. Fator de risco associado à infecção por Corynebacterium pseudotuberculosis em caprinos e ovinos criados no semiárido paraibano

\begin{tabular}{cccc}
\hline Fator de risco & Odds ratio & IC 95 \% & P \\
\hline Deixar o abscesso romper naturalmente & 8,19 & {$[1,75-38,25]$} & 0,008
\end{tabular}

favorecendo a infecção por Corynebacterium pseudotuberculosis (Langenegger et al. 1991). Outro fator que pode ser considerado determinante dessa alta frequência é a falta de medidas de controle sistemático nas fazendas, assim como a falta de controle no transporte e comercialização de animais, o que permite que animais infectados sejam introduzidos nos rebanhos (Souza et al. 2011).

Considerando a localização dos abscessos, observou-se que o linfonodo mais acometido foi o pré-escapular, com $50 \%$ do total de lesões encontradas em ambas as espécies. Esses resultados são semelhantes aos descritos por Silva \& Silva (1982), Unanian et al. (1985), Smith 
\& Sherman (1994) e Souza et al. (2011). Provavelmente isso se deve ao fato desses linfonodos serem responsáveis pela drenagem linfática de regiões do corpo mais frequentemente expostas a lesões provocadas pela vegetação espinhosa e tipos de cercados com arame e/ou vara trançada, comum nesta região, o que facilita a penetração da bactéria nos hospedeiros susceptíveis (Smith \& Sherman 1994).

Conforme resultados obtidos no isolamento e identificação dos microrganismos em abscessos superficiais, foi constatado isolamento de C. pseudotuberculosis em $68,2 \%(15 / 22)$ dos abscessos coletados, demonstrando a presença da infecção nos rebanhos caprinos e ovinos da região. Resultados similares foram constatados por Souza et al. (2011), que realizaram cultivo microbiológico em 51 linfonodos com lesões sugestivas de linfadenite caseosa em ovinos de abate e isolaram C. pseudotuberculosis em $43(74,5 \%)$ destes. Vale ressaltar que a real frequência de isolamento de C. pseudotuberculosis no presente trabalho pode estar mascarada, uma vez que foram investigados apenas linfonodos superficiais com lesões sugestivas.

No que se refere ao estudo de fatores de risco associados à ocorrência de linfadenite caseosa, o modelo final de regressão logística mostrou que o fato dos proprietários deixarem os abscessos romperem naturalmente está associado a um maior risco de ocorrência da infecção $(\mathrm{OR}=8,19)$. Tal fato é explicado pelo contato direto de animais sadios com doentes que apresentam abscessos rompidos, bem como pelo contato indireto com pastagem, instalações e utensílios contaminados com material proveniente dos abscessos. Observações referidas por outros autores apontaram o risco de contaminação ambiental por material de abscessos rompidos (Augustine \& Renshaw 1986, Batey 1986, Ellis et al. 1987). Dessa maneira, sugere-se que os caprinovinocultores da região devem adotar medidas profiláticas em seus rebanhos, como abertura e drenagem precoce dos abscessos superficiais e destino adequado do conteúdo. Tais medidas, associadas á inspeção periódica do rebanho, descarte de animais doentes e não introdução de animais infectados contribuirão significativamente para o controle desta doença).

Agradecimentos.- À Coordenação de Aperfeiçoamento de Pessoal de Nível Superior (CAPES) pelo apoio financeiro para a realização deste trabalho (Bolsa de Mestrado).

\section{REFERÊNCIAS}

Alves F.S.F., Santiago L.B \& Pinheiro R.R. 2007. Linfadenite caseosa: o estado da arte. Documentos, Embrapa Caprinos, Sobral. 60p.

Augustine J.L. \& Renshaw H.W. 1986. Survival of Corynebacterium pseudotuberculosis in axenic purulent exudate on common barnyard fomites. Am. J. Vet. Res. 47(4):713-5.

Batey R.G. 1986. Pathogenesis of caseous lymphadenitis in sheep and goats. Aust. Vet. J. 63:269-272.

Carvalho R.B. 2011. Potencialidades dos Mercados para os produtos derivados de caprinos e ovinos. Disponível em <http://www.capritec.com. br/art040521.htm> Acesso em 10 ago. 2011.

Ellis T.M. Shutherland S.S., Wilkinson F.C., Mercy A.R. \& Paton M.W. 1987. The role of Corynebacterium pseudotuberculosis lung lesions in the transmission of this bacterium to other sheep. Aust. Vet. J. 64:261-263.

Fontaine M.C. \& Baird G.J. 2008. Caseous lymphadenitis. Small Rum. Res. 76:42-48.

Hosmer Jr D.W. \& Lemeshow S. 1989. Applied logistic regression. Wiley, New York. 307p.

Langenegger J., Langenegger C.H. \& Scherer P.O. 1991. Prevalência e diagnóstico comparativo da linfadenite caseosa em caprinos do Estado do Rio de Janeiro. Pesq. Vet. Bras. 11:31-34.

Latorre M.R.D.O. 2004. Medidas de risco e regressão logística, p. 337-350. In: Massad E., Menezes R.X., Silveira P.S.P. \& Ortega N.R.S. (Eds), Métodos Quantitativos em Medicina. Manole, Barueri.

Medeiros J.X., Sano E.E. \& Ribeiro J.B.L. 2005. Cenário mercadológico da ovino-

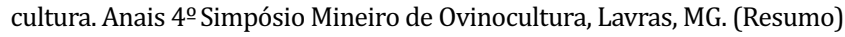

Murray P.R., Baron E.J., Pfaller M.A., Tenover F.C. \& Yolken R.H. 1999. Manual of Clinical Microbiology. $7^{\text {th }}$ ed. American Society for Microbiology, Washington, DC. 846p.

Radostits O.M., Gay C.C., Hinchcliff K.W. \& Constable P.D. 2007. Veterinary Medicine. $10^{\text {th }}$ ed. W.B. Saunders, Edinburgh, p.795-798.

Riet-Correa F. 2007. Linfadenite caseosa, p.347-352. In: Riet-Correa F., Schild A.L., Lemos R.A.A. \& Borges J.R. (Eds), Doenças de Ruminantes e Eqüídeos. $3^{\underline{a}}$ ed. Pallotti, Santa Maria.

Silva M.U.D. \& Silva A.E.D.F. 1982. Linfadenite caseosa em caprinos: observações clínicas de dois anos. Anais 18ํㅡㄹ Congresso Brasileiro de Medicina Veterinária, Santa Catarina, p.49.

Smith M.C. \& Sherman D.M. 1994. Goat Medicine. Lippincott Williams and Wilkins, Baltimore, p.46-49.

Souza M.F., Carvalho A.Q., Garino Jr F. \& Riet-Correa F. 2011. Linfadenite caseosa em ovinos deslanados abatidos em um frigorífico da Paraiba. Pesq. Vet. Bras. 31(3):224-230.

Thrusfield M. 1995. Veterinary Epidemiology. $2^{\text {nd }}$ ed. Blackwell Science, Cambridge. 479p.

Unanian M.M, Silva A.E.D.F. \& Pant K.P. 1985. Abscesses and caseous lymphadenitis in goats in tropical semi-arid Northeast Brazil. Trop. Am. Hlth Prod. 17:57-62.

Zar J.H. 1999. Biostatistical Analysis. $4^{\text {th }}$ ed. Prentice Hall, New Jersey. $663 p$. 